\title{
Lo vostre humil fill, qui us desiga molt veure. Cartas del apotecario rosellonés Joan Pereta desde Valencia a su padre en Perpiñán (1474-1479)
}

\author{
Lo vostre humil fill, qui us desiga molt veure. Letters by the Roussillon \\ apothecary Joan Pereta from Valencia to his father in Perpignan (1474-1479)
}

Luis Almenar Fernández luisalmenar@unizar.es Universidad de Zaragoza

Resumen: En este artículo se transcriben y estudian dos cartas personales, escritas por el apotecario Joan Pereta en la ciudad de Valencia en 1474 y 1479, y enviadas a su padre, el notario Jaume Pereta, a la villa de Perpiñán. Las misivas aportan información relevante para reconstruir cómo los flujos de información circulaban a finales de la Baja Edad Media en el espacio del Mediterráneo noroccidental, así como para indagar en la propia historia personal y familiar de Joan y Jaume Pereta. El lenguaje con el que se escribieron las cartas permite también explorar aspectos de mentalidad, como el fervor religioso de Joan y la relación de profundo respeto hacia su padre.

Palabras claves: correspondencia, cartas, información, rutas, mentalidades.

Abstract: In this article two personal letters are transcribed and studied. These were written by the apothecary Joan Pereta in the city of Valencia in 1474 and 1479, being sent to his father, the notary Jaume Pereta, to the town of Perpignan. The letters provide relevant information to reconstruct how information flows circulated at the end of the Late Middle Ages in the northwestern Mediterranean, as well as to investigate the personal and family history of Joan and Jaume Pereta. The language with which the letters were written also allows us to explore aspects of mentality, such as Joan's religious fervor and the relation of profound respect towards his father.

Keywords: correspondence, letters, information, routes, mentalities.

\footnotetext{
*El autor es beneficiario de una ayuda postdoctoral Juan de la Cierva-Formación del Ministerio de Ciencia e Innovación del Gobierno de España. Este trabajo se inserta dentro del proyecto "Desigualdad económica y movilidad social en la Europa mediterránea (siglos XIII-XVI)" (PROMETEO/2019/072) de la Generalitat Valenciana, así como del proyecto "¿Crecimiento sin desarrollo? Distribución de la riqueza, movilidad social y acción política en la Europa mediterránea (siglos XIII-XV)", del Ministerio de Ciencia, Innovación y Universidades (PGC2018-099275-B-I00).

Por otra parte, el autor desea agradecer a Aymat Catafau, Denis Fontaine, Vicent Royo y Javier Fajardo la ayuda prestada en la elaboración de este trabajo.
} 
Luis Almenar Fernández. Lo vostre humil fill, qui us desiga molt veure. Cartas del apotecario rosellonés Joan Pereta desde Valencia a su padre en Perpiñán (1474-1479)

\section{Introducción}

En una sociedad como la de la Europa del primer cuarto del siglo XXI, presa de la cultura de la inmediatez y de la exagerada comunicación interpersonal, permitida -e incentivada- por redes sociales y aplicaciones móviles, la correspondencia escrita física prácticamente ha desaparecido. Lo ha hecho, incluso, en el caso de las notificaciones oficiales emitidas por algunas instituciones públicas, y no queda prácticamente nada de las cartas escritas entre particulares, una excentricidad propia ya de nostálgicos y románticos que buscan el fetichismo del papel. Hasta hace solo unas generaciones, no obstante, la mensajería física era una realidad, presente en todo el mundo desde los inicios de las primeras civilizaciones históricas con cultura escrita. En la Europa de los siglos bajomedievales, desde luego, este sistema de comunicación fue activo y constante para lograr que la información -política, económica o, sencillamente, personal- fuera capaz de circular a través de espacios alejados, trascendiendo el boca a boca y las noticias que circulaban de la mano de viajeros (Poster / Mitchell 2007, Pontón 2002, Murphy 1986, Camargo 1991).

No son pocas, de hecho, las cartas que conservamos de época medieval, ni en la Península Ibérica ni en otros escenarios europeos. La inmensa mayoría de ellas se produjeron por importantes instituciones políticas, en la búsqueda de obtener información en el contexto de conflictos bélicos y diplomáticos, para asegurar el abastecimiento de las grandes urbes, o por un sinfín de otros motivos (Martín 2005, Richardson 2007: 52-66). Otro gran grupo de misivas resultaba de la búsqueda de las grandes compañías comerciales de la época de obtener información para hacer negocio en nuevos mercados, como la formada por el mercader italiano Francesco di Marco Datini (140.000 cartas conservadas en la ciudad toscana de Prato, datadas entre 1370 y 1410) (Orlandi 2008). La colección Datini es, sin lugar a dudas, la más conocida y mejor conservada de este tipo de documentación epistolar con finalidad comercial, pero cabe recordar que esta era una práctica habitual en otras compañías de tamaño más modesto y con menor recorrido temporal, aunque no por ello poco exitosas. Un caso recientemente estudiado en el ámbito peninsular es el de la compañía TorralbaManariello (1430-1448), cuyas operaciones se desarrollaron fundamentalmente entre Aragón, Cataluña e Italia (Viu Fandós, 2016: 125-146).

A parte de estos dos grupos de documentación epistolar, los más conocidos y estudiados, existía otro de carácter estrictamente personal y familiar, que únicamente buscaba mantener el contacto en la distancia con amigos y parientes informando sobre los hechos del día a día. Dentro de este grupo aún habría que distinguir entre otros dos subgrupos. Uno de ellos corresponde a las cartas escritas entre personajes de alta alcurnia, como miembros de la realeza y de la nobleza laica o eclesiástica (Cahner 1977-1978: vol. 1). Cabe destacar entre estos individuos también a las mujeres, reinas, nobles y princesas, que participaron activamente del intercambio de misivas privadas (Jardin / Marin / Rochwert-Zuili / Thieulin-Pardo 2020). El otro subgrupo lo constituyeron las cartas personales de carácter más "popular", escritas entre individuos de extracción no privilegiada, que se han conservado de manera muy extraordinaria. No solo porque haya que situarse en el contexto de

SCRIPTA, Revista internacional de literatura i cultura medieval i moderna, núm. 18 / desembre 2021 / pp. 57-80 ISSN: 2340-4841 · doi:10.7203/SCRIPTA.18.21716 
Luis Almenar Fernández. Lo vostre humil fill, qui us desiga molt veure. Cartas del apotecario rosellonés Joan Pereta desde Valencia a su padre en Perpiñán (1474-1479)

una sociedad en la que la mayor parte de la población no sabía leer ni escribir, sino porque, siendo documentos enviados y recibidos por individuos concretos, no han corrido la suerte de las cartas de las grandes instituciones, de las compañías mercantiles o de los sectores sociales más acomodados, que en buena medida pudieron buscar intencionadamente la conservación de esta documentación. Aun así, algunas de estas cartas más "populares" se han conservado de manera fortuita entre los registros de los notarios, cuando estos eran receptores de las misivas. Algunas de ellas se encuentran sueltas entre sus páginas, mientras que otras se hallan resguardadas en las cubiertas de pergamino de los protocolos notariales, y aún otras llegaron a coserse entre los hilos de la encuadernación (Ferrer i Mallol 1980: 197-217).

Los historiadores e historiadoras no han dejado pasar la oportunidad de estudiar estos documentos, que han ido publicando desde hace más de un siglo. La inmensa mayoría de ellos se corresponden singularmente con cartas encontradas en protocolos notariales catalanes, con independencia de que las misivas se enviaran desde otros lugares de la Corona de Aragón o del Mediterráneo. Caben destacar trabajos iniciales como el de Martorell (1926: 22-24), en el que se recogen más de setenta cartas personales, así como otros estudios centrados en colecciones más reducidas de misivas (por ejemplo, Serra i Ràfols 1952: 25-31). Los trabajos especializados en esta temática se aceleraron con claridad, no obstante, desde finales de la década de los 1970, en consonancia con un creciente interés por la documentación notarial, que hubo de llevar a acumular los hallazgos fortuitos de estas cartas. Algunos trabajos fundamentales se realizaron entonces, como los de Ferrer i Mallol (1974: 29-191, 1980: 197-217), Vinyoles Vidal (1984: 387-420), Cahner (1977-1978) y Riu (1979: 501506), en los que se estudian y transcriben decenas de cartas. Las publicaciones de estas misivas han continuado desde entonces, dando lugar a estudios recientes como los de Navarro Bonilla (2003: 11-32) o Lozano Gracia (2007: 139-170), así como a otros de Vinyoles Vidal (1996: 111-198, 2000: 555-566, 2003-2004: 445-460).

Con el fin de ampliar el corpus disponible de esta documentación de conservación extraordinaria, en este artículo se estudian y transcriben dos ejemplares inéditos de finales del siglo XV, hallados entre los fondos de los Archives Départementales des Pyrénées-Orientales de la villa de Perpiñán. Se trata de dos cartas del apotecario rosellonés Joan Pereta, que envió a su padre, el notario Jaume Pereta, desde la ciudad de Valencia a la capital del Rosellón. Las misivas no versan de grandes asuntos políticos ni diplomáticos, a pesar de que se redactaron en años muy convulsos particularmente en Perpiñán, y en Cataluña en general -el Rosellón formó parte del principado hasta su anexión al reino de Francia en 1659, mediante el Tratado de los Pirineos. Tampoco incluyen información económica sobre potenciales clientes para fines comerciales. Son dos cartas cuyo contenido, profundamente íntimo y personal, arrojan luz sobre un contexto familiar marcado por el miedo a perderse la pista y por la voluntad incansable del reencuentro. Es, en definitiva, la situación particular de un padre y un hijo muy lejos el uno del otro, situados cada uno en un extremo de la Corona de Aragón peninsular. Pero, además, ambos documentos ayudan a comprender cómo la correspondencia privada circulaba por los diversos espacios de la Corona de Aragón a finales de la Edad Media y, de manera más global,

SCRIPTA, Revista internacional de literatura i cultura medieval i moderna, núm. 18 / desembre 2021 / pp. 57-80 ISSN: 2340-4841 · doi:10.7203/SCRIPTA.18.21716 
Luis Almenar Fernández. Lo vostre humil fill, qui us desiga molt veure. Cartas del apotecario rosellonés Joan Pereta desde Valencia a su padre en Perpiñán (1474-1479)

cómo la propia información -sobre personas, acontecimientos y situaciones diversas- transitaba de un lugar a otro, a través de una red tejida de contactos personales. El tono de la carta, cargado de emociones y sentimientos, permiten también profundizar en verdaderos aspectos de mentalidad, como en la devoción cristiana de Joan y en la relación de profundo respeto hacia su padre. Son dos cartas, además, que hablan de muchas otras que nunca llegaron a su destino, y que Joan y Jaume estuvieron enviándose hasta ponerse finalmente en contacto, para lo que hizo falta la intervención de amigos y conocidos, así como el recurso a una de las rutas de navegación más importantes del Mediterráneo de la época.

\section{Valencia, Perpiñán y los flujos de información a finales del Cuatrocientos}

Durante la década de 1470, en la cual fueron redactadas las dos cartas aquí estudiadas, Valencia y Perpiñán conformaban dos de las urbes más grandes y poderosas de la Corona de Aragón. La ciudad de Valencia, de hecho, era la más poblada de toda la Península Ibérica, alcanzando los 8.840 fuegos en 1487, y llegando casi a los 10.000 en 1510 (Valldecabres 2002). La hegemonía demográfica que la capital del reino de Valencia alcanzó en el espacio peninsular no solo se explicaba por el éxito económico y el dinamismo social que arrastraba desde los siglos precedentes, y que se manifestaba, entre otras cosas, en la atracción constante de inmigrantes. También supuso un factor importante el declive de Barcelona, resentida por los efectos destructivos de la Guerra Civil Catalana, que emergió del conflicto abierto entre la Generalitat y Juan II entre 1464 y 1472 (Salrach / Duran 1980: 1000-1006).

La villa de Perpiñán, por su parte, constituyó una población urbana de grandes dimensiones a finales del siglo XV, cuya población se situaría en 2.962 fuegos en 1497, gozando de una relevancia comercial destacada y de una importante producción pañera local (Feliu 1999: 27). El Rosellón y la Cerdaña, condados que formaban parte integral del principado de Cataluña durante el siglo XV, fueron ocupados por Luis XI de Francia desde 1463, en presunto auxilio al rey Juan II contra sus súbditos rebeldes, precipitando en la práctica una buscada incorporación de los condados al reino francés. La Cataluña ultrapirenaica se organizó desde entonces y mientras se desarrollaba la guerra civil bajo la forma de nuevas senescalías, regidas por franceses o miembros de la nobleza rosellonesa profrancesa, enriquecidos por los bienes confiscados a quienes se opusieron a la ocupación. Acabada la guerra en 1472, Juan II reavivó sus alianzas con la nobleza rosellonesa y desarrolló una ofensiva antifrancesa que se prolongaría un año, durante el cual Luis XI intentó mantener un dominio en la zona que le llevó, entre otras cosas, a sitiar la ciudad de Perpiñán. La resistencia de la villa llevó finalmente a la firma de un tratado de paz en 1473, que establecía una especie de comandancia compartida de los condados entre Luis XI y Juan II. El monarca francés no tardó en romper el acuerdo, invadiendo de nuevo el territorio y sitiando una vez más Perpiñán, esta vez durante ocho duros meses, en los que la capital rosellonesa se negó a rendirse hasta que lo ordenara el rey Juan. Este aceptó la rendición finalmente el 10 de marzo de 1475, episodio que

SCRIPTA, Revista internacional de literatura i cultura medieval i moderna, núm. 18 / desembre 2021 / pp. 57-80 ISSN: 2340-4841 · doi:10.7203/SCRIPTA.18.21716 
Luis Almenar Fernández. Lo vostre humil fill, qui us desiga molt veure. Cartas del apotecario rosellonés Joan Pereta desde Valencia a su padre en Perpiñán (1474-1479)

conferiría a la urbe el título de "fidelíssima vila", que conserva en la actualidad, y al que seguirían veinte años de dominio francés (Salrach / Duran 1980: 948-949, 953-954, 997-1000). Las tentativas de incorporación al reino de Francia, desde luego, proseguirían en los siglos venideros, hasta su consumación final y definitiva en el siglo XVII.

Valencia y Perpiñán, la capital de un reino y la de un condado, tenían, en realidad, un tipo de sociedad similar, profundamente urbana. Dentro de sus muros se agolpaba una efervescente población de artesanos, de clérigos - cabe recordar que ambas eran sedes catedralicias-, de notarios, de campesinos, de caballeros, y de mercaderes. No podía ser de otra manera teniendo en cuenta la importante proyección comercial, de carácter profundamente internacional, y el papel geoestratégico de los territorios de los que eran capitales, que conectaban el Mediterráneo, la Península Ibérica y la Europa continental. El flujo de correspondencia entre ambas urbes debió de gozar sin lugar a dudas de una actividad similarmente muy elevada, tanto en lo que respecta a misivas de carácter mercantil como a aquellas de tipo personal. Y es que desde principios del siglo XIV había cristalizado en el Mediterráneo un verdadero "sistema postal", muy complejo y desarrollado, que permitía que la información circulara con acusada celeridad desde el mar del Norte al Mediterráneo en apenas unas semanas (Pifarré 1999: 683-697). Existían, de hecho, tres mecanismos íntimamente relacionados mediante los cuales las cartas circulaban por la Europa del momento, conectando entre muchos otros lugares Valencia y Perpiñán.

El primero y el que más volumen epistolar movía era el sistema de la escarcella, llamado así por el saco de cuero del mismo nombre en el que se depositaban las cartas antes de cerrarlo con una cuerda y sellarlo, para evitar que nadie las leyera antes de llegar a su destino sin dejar rastro. Se trataba, en efecto, de un servicio postal regular a gran escala, que organizaban las grandes compañías mercantiles del momento en la búsqueda por asegurar una circulación eficiente, segura y discreta de las cartas mercantiles en las que se transmitía información sobre el estado de los mercados. El servicio, no obstante, se prestaba a otras sociedades más modestas o a particulares. Se pagaba por número y peso de cartas, y se operaba entorno a unos plazos de entrega, con penalizaciones si las misivas llegaban tarde a su destino. En la mayor parte del trayecto entre Perpiñán y Valencia coexistía la escarcella dels catalans y la escarcella dels italians, siendo solo algunas de entre las varias escarcellas que existían cubriendo los espacios entre Brujas y Barcelona. Desde esta última ciudad discurría una ruta hacia Italia, siendo Perpiñán precisamente una de las principales escalas previas, junto a Montpellier y Aviñón. Valencia era, por su parte, una parada esencial hacia el sur en la circunvalación de la Península Ibérica (Pifarré 1999: 689). Las relaciones entre Valencia y Barcelona fueron activísimas por vía marítima. Casi cada día salía un barco hacia Valencia desde Barcelona, que llegaba en una media de 4 días (Pifarré 1999: 695-696).

El flujo epistolar no estaba en manos solamente de mercaderes. Ya desde finales del siglo XIV la escarcella coexistía con un sistema especializado de mensajería llevado a cabo por hostes de correus o mestres de correus, auténticos profesionales del envío y recepción de misivas, que gestionaban la

SCRIPTA, Revista internacional de literatura i cultura medieval i moderna, núm. 18 / desembre 2021 / pp. 57-80 ISSN: $2340-4841 \cdot$ doi:10.7203/SCRIPTA.18.21716 
Luis Almenar Fernández. Lo vostre humil fill, qui us desiga molt veure. Cartas del apotecario rosellonés Joan Pereta desde Valencia a su padre en Perpiñán (1474-1479)

circulación de cartas como un negocio al margen de la escarcella. Estos eran capaces de gestionar entregas por vía fluvial y terrestre, a pie, y dieron lugar a un servicio muy activo y regular, al que no solo recurrían los particulares, sino también algunas sociedades de mercaderes. Un caso muy significativo es el de la mencionada compañía mercantil Torralba-Manariello, que empleó el sistema de la escarcella al menos entre 1430 y 1432, optando desde 1434 por recurrir a un hoste de correus para el envío de sus misivas (Viu Fandós 2016: 131).

Cabe identificar, finalmente, formas de transmisión de la información por vía epistolar de carácter más informal, no institucionalizadas bajo las dos formas anteriores. La movilidad sobre todo marítima de mercaderes, hombres de negocios, peregrinos, soldados, patrones de nave, en definitiva, viajeros de naturaleza diversa actuaba igualmente como un flujo adicional de misivas, pues muchos de estos individuos llevaban cartas personales consigo (Viu Fandós 2016: 134, Pifarré 1999: 691).

\section{Dos cartas, un hijo y un padre}

Las cartas de Joan Pereta se redactaron en la ciudad de Valencia el 25 de abril de 1474 y el 9 de agosto de 1479. Ambas se conservan en los Archives Départementales des Pyrénées-Orientales, situados en Perpiñán, en dos fondos muy diferentes. La misiva de 1474 se conserva como un folio suelto no numerado dentro de un volumen de los registros de la Procuració Reial, la institución que administraba territorialmente los condados ultrapirenaicos de Cataluña dentro del conjunto de la Corona de Aragón. ${ }^{1}$ Su presencia aquí resulta difícil de explicar. Es posible que Jaume Pereta, el padre de Joan, trabajara para la institución en paralelo al ejercicio de su actividad laboral en la oficina notarial o que, sencillamente, la carta se haya traspapelado desde sus registros notariales, que se conservan en el mismo archivo. Es entre estos últimos donde se encuentra la otra carta de Joan Pereta, redactada en 1479, entre los pliegos sueltos de un registro de inventarios, subastas públicas (encants) y otros documentos relacionados con el derecho privado, como testamentos y codicilos. ${ }^{2}$ Ambas cartas presentan signos de reutilización, mostrando la de 1474 algunas rallas y garabatos, así como varias cifras en números romanos que quizás sean cuentas personales. La segunda, de 1479, fue reaprovechada para escribir un documento notarial. En el espacio del medio folio que quedaba en el dorso de la carta, Jaume Pereta anotó las últimas disposiciones de un testamento escrito en latín, fechado a 30 de agosto de 1479. Esta fecha, 21 días posterior a la de la redacción de la carta, revela así el tiempo que como mucho tardó esta segunda misiva en llegar a Perpiñán desde Valencia, de las manos de Joan a las de Jaume. La carta, en realidad, debió de llegar a su destino mucho antes, si consideramos los ritmos de la correspondencia

\footnotetext{
1 Archives Départementales des Pyrénées-Orientales (ADPO), 1B223, folio suelto (Doc. 1, de ahora en adelante). Deseo agradecer la amabilidad inmensa de Vicent Royo al haberme proporcionado una copia digitalizada de esta carta, que localizó en este archivo hace más de una década. Sobre la institución de la Procuració Reial y la gobernanza de los territorios de la Cataluña ultrapirenaica véase Saguer 2020.
}

2 ADPO, 3E1/1202, fol. 64 (Doc. 2, de ahora en adelante).

SCRIPTA, Revista internacional de literatura i cultura medieval i moderna, núm. 18 / desembre 2021 / pp. 57-80 ISSN: 2340-4841 · doi:10.7203/SCRIPTA.18.21716 
Luis Almenar Fernández. Lo vostre humil fill, qui us desiga molt veure. Cartas del apotecario rosellonés Joan Pereta desde Valencia a su padre en Perpiñán (1474-1479)

en la época, que eran bastante rápidos incluso por tierra. Una misiva podía llegar a Barcelona desde Zaragoza en una semana, o en cuatro días y medio si era un correo urgente (Viu Fandós 2016: 140). En el caso de la correspondencia marítima, la escarcella hacía viable que una misiva recorriera el trayecto completo de Brujas a Barcelona en una media de 23 días (Pifarré 1999: 695).

Formalmente, ambas misivas se redactaron en una escritura gótica catalana con una caligrafía de lectura muy correcta y con la presencia de las abreviaturas y suspensiones habituales de la época. En ambos casos el contenido del texto se escribió en una cara de folio, que posteriormente fue doblado seis o siete veces, utilizando uno de los espacios libres del dorso para escribir el nombre y dirección del destinatario. Así pues, el ejemplar de 1474 va dirigido "Al molt amat e car pare lo senyor en Jaume Pereta, notari, prop la Font Nova. En Perpinyà”, mientras que el de 1479, en un tono más aséptico, menos personal, lo hace "Al molt honorable senyor Jaume Pereta, notari, prop la Font Nova. En Perpinyà". En ambos casos se incluyeron, además, algunas frases que ayudan a deducir el sistema de correspondencia empleado para el envío de las cartas. En el dorso de la carta de 1474 se anotó en la parte inferior izquierda "per amich", una indicación habitual en el sistema epistolar bajomedieval para hacer constar por escrito que el emisor esperaba que la misiva la entregara al receptor un amigo. Pueden encontrarse ejemplos similares en otras cartas personales transcritas y publicadas (Martorell 1926: 61, $63,117)$, así como en la correspondencia de la mencionada compañía Torralba-Manariello, con frases como "date per amice" y “detur per amic" (Viu Fandós 2016: 134). Existían expresiones similares si el portador era un pariente ("parente") y, en ocasiones, se indicaba explícitamente el nombre completo del portador (Viu Fandós 2016: 134). En el caso de la misiva de Joan Pereta ese "amich", como se desvela en el contenido de la misma, iba a ser un paisano rosellonés también residente en Valencia, el hijo de Tardiu. Con todo, incluso en el momento de la redacción Joan dudaba de si le entregaría finalmente la carta a él o a Antoni Reys, quien también iba a regresar pronto a Perpiñán, precisamente junto a Tardiu, en la misma gal tera florentina. ${ }^{3}$

En el caso de la misiva de 1479 no hay indicaciones sobre quién debía entregar la carta -no la hay, de hecho, tampoco en el cuerpo del texto-, por lo que cabe deducir que el portador fue un mensajero de alguno de los servicios profesionales de mensajería aludidos anteriormente. De hecho, en este caso lo que se anotó en el exterior de la misiva fue la ruta por la que debía transitar la carta, "per via de Barchinona" (Doc. 2). Encontramos indicaciones similares en el dorso de algunas de las cartas personales publicadas encontradas en otros archivos catalanes. Así puede verse en la carta que Pere Villardell envió desde Ibiza al notario Guerau Gili, que se hallaba en Barcelona, la cual circularía "per via de València" (Martorell 1926: 141). En el cuerpo del texto de la misiva de 1479 Joan Pereta también indicaba a su padre que la carta iba a Vinçà, una localidad de la Cataluña ultrapirenaica localidad a unos $35 \mathrm{~km}$. al oeste de Perpiñán siguiendo el curso del río Têt, el cual atraviesa ambas

3 “Lo portador de la present, lo qual me pens serà lo fill d'en Tardiu, vos avisarà de mi, o per lo semblant lo desús dit Antoni Reys vos avisarà també, car abdós se’n van aquí ensemps ab la gal lera florentina” (Doc. 1).

SCRIPTA, Revista internacional de literatura i cultura medieval i moderna, núm. 18 / desembre 2021 / pp. 57-80 ISSN: $2340-4841 \cdot$ doi:10.7203/SCRIPTA.18.21716 
Luis Almenar Fernández. Lo vostre humil fill, qui us desiga molt veure. Cartas del apotecario rosellonés Joan Pereta desde Valencia a su padre en Perpiñán (1474-1479)

poblaciones. ${ }^{4}$ Parece, pues, que Joan asumía que el trayecto que seguiría la carta iba a ser de Valencia a Barcelona por mar, y desde ahí por tierra a Vinçà, desde donde seguramente las cartas continuarían su itinerario hasta Perpiñán en barco, siguiendo el curso del río Têt. Este desvío, extraño si asumimos que la carta podría haber llegado directamente a Perpiñán por mar desde Barcelona, quizás guarde alguna relación con el hecho de que los notarios Pereta de Perpiñán mantenían estrechas relaciones personales con familiares en Vinçà y Argelers, como están revelando estudios prosopográficos aún no publicados (Fontaine, inédito). ${ }^{5}$

El ejemplar de 1474, por otro lado, conserva lo que parece ser el signum personal de Joan Pereta, una filigrana consistente en una línea vertical, que se inicia en la parte superior con unas aspas, seguida por una cruz rematada con círculos, que se convierte finalmente en una letra "P" mayúscula, cuyo trazo inferior vuelve sobre sí para crear la abreviatura "er", de "Pereta" (Véase Figura 1). En ninguno de los dos casos se han conservado restos de los sellos de cera con los que se cerraban estos documentos (Martorell 1926: 19-20, Viu Fandós 2016: 139).

Figura 1. Imagen del dorso de las cartas de Joan Pereta de 1474 y 1479
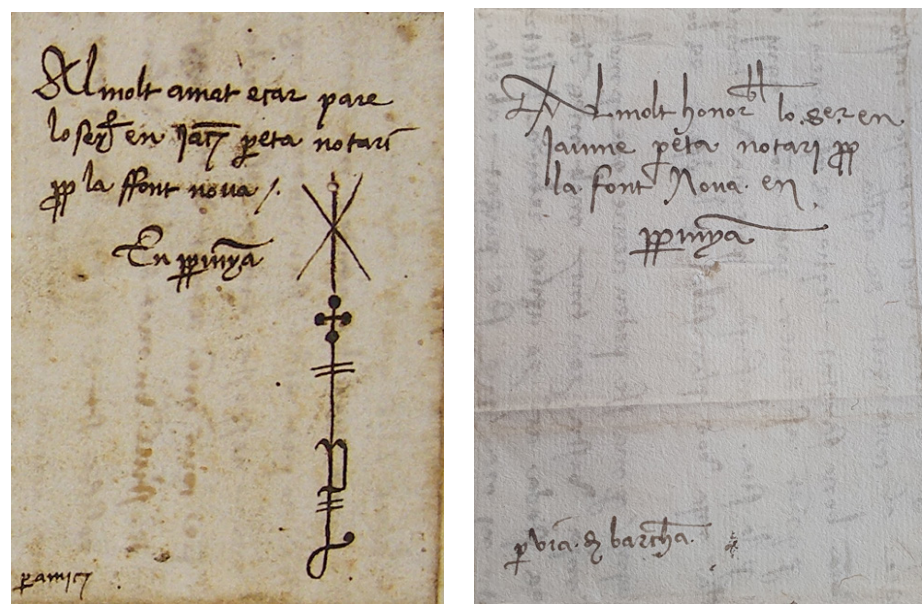

Estos aspectos formales son plenamente coincidentes con aquellos que se observan en este tipo de correspondencia privada (por ejemplo, Martorell 1926: 18-20), los cuales no dejan de ser los mismos que los de las cartas de carácter más mercantil (Viu Fandós, 2016: 138-140). En ambos casos, como en el de las cartas aquí presentadas, el texto se abre con la invocación Ihesus o Ihesus Christus, dirigiéndose por primera vez al destinatario como molt alt o molt honorable. Tras un cuerpo de texto donde se transmite la información deseada, se llega a un párrafo de cierre de conversación, indicado por la expresión "no

\footnotetext{
4 "la present letra aga bon recapte, que va a Vinçà". Doc. 2.

5 Deseo agradecer a Denis Fontaine su enorme amabilidad al hacerme llegar este trabajo.
} 
Luis Almenar Fernández. Lo vostre humil fill, qui us desiga molt veure. Cartas del apotecario rosellonés Joan Pereta desde Valencia a su padre en Perpiñán (1474-1479)

he més a dir" en el caso de las misivas de Joan (Docs. 1 y 2) Aquí se transmiten los mejores deseos para el destinatario y sus familiares, antes de cerrar el texto definitivamente con una despedida (Martorell 1926: 19; Viu Fandós 2016: 139). Resulta evidente que Joan Pereta estaba plenamente familiarizado con los formalismos y convenciones propios de una escritura epistolar ya plenamente establecida y consolidada, que ya a inicios de época moderna quedaría sistematizada en formularios y manuales especializados (Mesquida 2003: 317-329, Iciar 1552, Castillo Gómez 2002: 79-107, Gimeno Blay 2005: 23-36).

Por otra parte, el buen uso de la sintaxis que Joan Pereta emplea en ambas cartas va de la mano con una coherencia muy lograda en el uso de la escritura, que se presenta consistente y solamente en ocasiones vacila entre letras, escribiendo, por ejemplo, "altre letra". ${ }^{6}$ No cabe duda de que Joan, hijo de un notario, había seguido los pasos de su padre y había recibido una educación que le había llevado a un grado de alfabetización alto, que sobrepasaba una mera familiarización funcional con el uso de la escritura. Como se ha mostrado anteriormente, su primera carta incluye su signum personal, y la segunda, por su parte, acaba firmada no solo con su nombre, sino con su oficio: apotecari. Joan solamente anotó la indicación de su oficio en la segunda carta, quizás como un signo de honor de cara a su padre. ${ }^{7}$

Los apotecaris o boticarios (también llamados especiers en Valencia) se dedicaban a la preparación y venta de productos considerados medicinales en la época, como jarabes y purgas. Se trataba de un trabajo altamente especializado, que requería de un largo período de aprendizaje y del asentamiento de unos conocimientos complejos que implicaban el uso frecuente de la escritura, sobre todo para los maestros y los aspirantes a este rango (Ferragud 2007: 48-57). Este uso era necesario para la confección de recetas para los clientes, las cuales, desde las cortes celebradas en Valencia por Alfonso el Magnánimo entre 1417 y 1418, podían redactarse "en aquell lenguatge en què l'especier qui les haurà a confegir les puga bé entendre" (Martínez Vinat 2018: 574). El oficio se fue desarrollando desde principios del siglo XIV, y a mediados del siglo XV se hallaba ya plenamente regulado como art e sciència, una consideración superior a la de ofici o gremio, con la que se denominaba a trabajos menos cualificados, más manuales y físicos (Martínez Vinat 2018: 576, 573-581). De hecho, en 1441 la reina María de Castilla, lugarteniente del monarca Alfonso el Magnánimo, otorgó el privilegio que autorizaba la creación de un col legi d'apotecaris en la ciudad de Valencia, permitiendo un modelo de asociación de mejor consideración que el de la cofradía, que era el aplicado a la mayoría de oficios. El establecimiento de esta institución fue el resultado, precisamente, de lo mucho que había aumentado el número de boticarios en los años precedentes, como revela la solicitud que hicieron a la reina los impulsores del colegio, examinadores del arte, que argumentaban que "nostre Senyor Déu los ha multiplicats, com en temps passat fossem pochs” (Martínez Vinat 2018: 576).

El establecimiento de Joan Pereta en Valencia y el ejercicio de su actividad como boticario en el cap i casal se desarrolló, pues, en uno de los mejores momentos de la profesión, en pleno proceso de

6 "La causa de la present serà per avisar-vos com air que que (sic) teníem XXIIII vos he scrit per altre letra” (Doc. 1).

7 “Lo vostre humil fill, qui us desiga molt veure. Johan Pereta, apotecari” (Doc. 2).

SCRIPTA, Revista internacional de literatura i cultura medieval i moderna, núm. 18 / desembre 2021 / pp. 57-80 ISSN: 2340-4841 · doi:10.7203/SCRIPTA.18.21716 
Luis Almenar Fernández. Lo vostre humil fill, qui us desiga molt veure. Cartas del apotecario rosellonés Joan Pereta desde Valencia a su padre en Perpiñán (1474-1479)

expansión e institucionalización. En Valencia, además, al menos desde 1443 era necesario tener 24 años para poder desempeñar esta actividad (Rodrigo Pertegás 1929: 119), lo que nos da una idea aproximada de la edad que pudo haber tenido Joan Pereta. Este debió de ser un adulto joven, cercano o recientemente adentrado en la treintena, que probaba las oportunidades de un oficio en auge en una de las ciudades más importantes del Mediterráneo noroccidental. Sus cartas, muy interesadas en comunicar su situación de bienestar personal a su padre, y en preocuparse por la de este último y la de sus familiares en Perpiñán, no hacen referencia alguna a la existencia de una familia propia consolidada en Valencia, llevando a imaginarlo como soltero y sin hijos.

De quien puede saberse mucho es de Jaume Pereta, gracias al excepcional trabajo de investigación prosopográfica de Denis Fontaine sobre los notarios de Perpiñán. Los Pereta constituyeron un linaje de notarios presente en la Cataluña ultrapirenaica desde finales del siglo XIII, diseminados entre Vinçà, Argelers y Perpiñán. Jaume Pereta habría vivido al menos entre 1451 y 1483, siendo descendiente de Guillem Pereta, también notario de Perpiñán, estando directamente emparentado con los Pereta de Vinçà de aquel momento. De alguna manera, como se ha expuesto anteriormente, esta relación debe de explicar por qué la carta de Joan de 1479 iría de Barcelona a Perpiñán pasando por Vinçà. La dirección de destino de las cartas que Joan enviaba desde Valencia era prop de ("cerca de") la Font Nova. Esta fuente constituyó un punto de referencia de la villa de Perpiñán desde su construcción a finales del siglo XIV, y siguió siéndolo hasta su destrucción definitiva a finales del siglo XIX (Puig / Carozza / Durand 2015: 68-69, Catafau / Bergeret / Fontaine / Recolin 2014 : 159-174, Camps 1973). Se situaba en una de las principales arterias del entramado urbano, que partía desde la antigua puerta de Elna, al sureste de la villa, hasta la Font Nova, donde se bifurcaba en dirección oeste hacia la plaça de les Corts, y en dirección noroeste hacia el convento de los Dominicos, atravesando el resto de la villa (Puig / Carozza / Durand 2015: 73). ${ }^{8}$ Se trataba de una zona de gran dinamismo y de un importante tránsito de población en una villa que destacaba por ser el principal centro de mercado de la zona. Es posible, pues, que más que la residencia de Jaume Pereta, cerca de la Font Nova se situara su oficina, cercana al bullicio de una masa cambiante de clientes, y donde guardaría los registros notariales entre los que acabó guardando las cartas de su hijo Joan. Sabemos, además, que fue propietario desde 1480 -desde un año después de recibir la última carta de Joan- de una casa en la parroquia de Sant Joan cercana a la plaça de les Cebes, donde quizás vivió desde entonces (Fontaine, inédito) (Figura 2, Figura 3).

Durante los años en los que Joan escribía a Jaume desde Valencia, este último estuvo casado con una mujer llamada Caterina, la cual contrajo matrimonio con Jaume en segundas nupcias. Es seguramente la Catarina/Cathalina que se menciona las cartas. La falta de mención de Joan a una mare en ambas misivas es muy llamativa, más aun teniendo en cuenta que en ambas sí que traslada sus mejores deseos a una tia. Es posible que Caterina fuera más bien la madrastra de Joan, quien residiría en Perpiñán con su padre y sus cuatro hermanas aún pequeñas, "aquexes infantes", como las llamaba Joan (Doc. 2): Aldonça, Joana, Honorada y Margarida. Una de ellas, Margarida, quizás falleciera en algún momento de los años transcurridos entre ambas cartas, dada la falta de mención a ella en el ejemplar de 1479,

8 Deseo agradecer a Aymat Catafau el haberme sugerido la bibliografía indicada para la localización de la Font Nova de Perpiñán.

SCRIPTA, Revista internacional de literatura i cultura medieval i moderna, núm. 18 / desembre 2021 / pp. 57-80 ISSN: $2340-4841 \cdot$ doi:10.7203/SCRIPTA.18.21716 
Luis Almenar Fernández. Lo vostre humil fill, qui us desiga molt veure. Cartas del apotecario rosellonés Joan Pereta desde Valencia a su padre en Perpiñán (1474-1479)

en contraste con el de 1474 (Docs. 1 y 2). Las otras tres sobrevivieron muchos años, desposándose con hombres de buena posición de Perpiñán. Aldonça lo hizo con un mercader llamado Francesc Torres y Joana con el notario Hugo Pujol, con quienes estaban casadas en 1549, exactamente 70 años después de la redacción de las cartas de Joan. Honorada contrajo matrimonio con Pere Cori, también mercader, con quien estuvo casada al menos en 1477 (Fontaine, inédito).

\section{Carta del 25 de abril de 1474}

La carta más antigua que conservamos de Joan Pereta, escrita en la ciudad de Valencia el 25 de abril de 1474, fue redactada como resultado de un largo período de falta de contacto y comunicación con su padre, hasta el punto de que desconocía "si és mort ni viu" (Doc. 1). Las preguntas acerca de su bienestar personal ocupan la mayor parte del texto de la misiva, así como las referencias a las muchas otras cartas desesperadas que le había escrito, que revelan la red de conocidos, amigos y familiares a los que recurrió para establecer contacto epistolar con Jaume.

Previamente a la redacción de la misiva del 25 de abril 1474, Joan redactó al menos una docena de cartas desde Valencia. Algunas de ellas las enviaba directamente a Jaume a Perpiñán, a la vez que mandaba otras a allegados y conocidos de otros lugares de Cataluña. Joan llevaba ya mucho tiempo escribiendo a un primo hermano suyo, Pere Torís, residente en Barcelona, preguntándole por el paradero de su padre. Joan escribió a Torís hasta la saciedad, tantas cartas que el propio Joan dudaba, al contárselo a su padre, de si ya le había enviado diez o quizás 12 cartas a Barcelona, como en el caso de esta misiva, "per amichs", es decir, recurriendo a conocidos de confianza. ${ }^{9}$ Pere Torís, además de un familiar cercano, debía de ser un mercader o, al menos, alguien que se trasladaba con cierta frecuencia entre el espacio que separaba a Joan y Jaume, y que tendría un contacto recurrente o periódico con ambos. Joan, de hecho, parafrasea para su padre parte del mensaje escrito en las cartas a Torís, en las cuales le insistía a su primo hermano que le informara del paradero de su padre, pues no tenía otro medio para saber de él: "perquè ya sabeu que d'ell [de su padre] may n'auria noves sinó per mityà vostre [de Torís]") (Doc. 1). Torís no le informaba de absolutamente nada, le afirmaba a su padre, "ni per letra ni per paraula", y aún le confesaba que pensaba que lo hacía a propósito, y no tenía reparo en interpretar que su primo hermano no le tenía en gran estima: "tinch a creure me vol mal de alguna cosa" (Doc. 1).

Joan Pereta no solo trataba de saber de su padre Jaume a través de contactos, como podía ser su primo hermano. Esto no era más que una solución auxiliar, complementaria a las muchas cartas que escribía directa y frecuentemente desde Valencia a Perpiñán, dirigidas todas ellas a su padre, desde hacía casi un año, como calculaba el propio Joan. ${ }^{10}$ Esta precaución por "diversificar riesgos" enviando

\footnotetext{
9 “dich-vos que per amichs sseus yo li he scrit X ho XII letres que may no m’a volgut ffer resposta” (Doc. 1).

10 "prech-vos nos scrigam ssoviynt e que comensseu vós ara, per quant yo he comenssat ja haurà un jorn d'aquests un anyn" (Doc. 1).
} 
Luis Almenar Fernández. Lo vostre humil fill, qui us desiga molt veure. Cartas del apotecario rosellonés Joan Pereta desde Valencia a su padre en Perpiñán (1474-1479)

múltiples copias de la misma misiva simultáneamente era una práctica habitual en la época, tanto en la correspondencia de carácter personal como en la de fines comerciales (Martorell 1926: 20-21, Pifarré 1999: 687, Pifarré 2002: 51). De hecho, el joven boticario había escrito y enviado una carta justo un día antes de la misiva del 25 de abril de 1474. Esta debía llegar a Perpiñán de manos de Curós Teixidor, cuyo propósito para el viaje desconocemos, así como la ruta o método de viaje que empleó. ${ }^{11}$ La carta del día 25, sin embargo, debía llegar a Perpinyà en manos, en este caso, de Antoni Reis o de "el hijo de Tardiu", quienes volverían juntos desde Valencia a Perpiñán por mar, concretamente, en una "gal lera florentina" (Doc. 1). Como Joan Pereta, Antoni Reis y Tardiu júnior debían de ser jóvenes roselloneses, migrantes, podría decirse, en búsqueda de las oportunidades de promoción social de una gran urbe en expansión, moviéndose por la Corona de Aragón a través de una de las rutas marítimas más importantes del Mediterráneo del momento. El motivo de la vuelta a Perpiñán de Reis y Tardiu, revelado por la carta, más que económico, era personal, pues al parecer el padre de Tardiu había fallecido. ${ }^{12}$ Tardiu hijo vivía en Valencia bajo el amparo económico de un mercader (había "trobat recapte"), como informa Joan a su padre, pero había tenido que acabar con esta relación para volver a Perpiñán lo que se entrevía como un largo período de tiempo. Joan esperaba que Tardiu hijo no solo le entregara la carta a Jaume, sino que, en esa estancia en la capital rosellonesa, le pudiera contar de palabra y al detalle sobre el día a día de Joan en la capital del reino de Valencia ("ell ssó sert vos avisarà de mi”. (Doc 1)).

El resto del contenido de la carta tiene un carácter fundamentalmente emocional. Joan da gracias a Dios por encontrarse bien, y ruega al mismo que alguna de sus cartas llegue a su destino, y que cuide de su padre y de su familia. Le pide a su padre que se escriban a menudo, más en ese momento en el que "lo pasatge stà ubert". Sin más detalles, la referencia está abierta a interpretaciones de muy diferentes dimensiones. La Guerra Civil Catalana, finalizada solo dos años antes de la redacción de la carta, las ocupaciones del territorio rosellonés por las tropas de Luis XI de Francia, o las revueltas antifrancesas constituyeron momentos de inestabilidad política y social que explicarían fácilmente un corte, intermitente o prolongado, en las rutas de comunicación de los diferentes territorios de la Corona de Aragón (Salrach / Duran 1980: 1003). En última instancia, es posible que esto explique la falta de contacto epistolar que padre e hijo habían estado teniendo, y la voluntad casi desesperada de Joan por saber de Jaume. Aún más, esto justificaría la insistencia de Joan por saber si su padre seguía vivo.

Todo este turbulento contexto histórico, que sin duda alguna afectó a las vidas de los familiares de Joan, curiosamente, no es referido ni una sola vez, ni en esta carta ni en la de 1479. Más llamativo es en el caso de esta última, en la que no hay referencia alguna a los muchos meses de sitio que aguantaron los perpiñaneses frente a los franceses en 1475, ni a las revueltas antifrancesas que se sucedieron durante los años siguientes (Salrach / Duran 1980: 1000). En una carta de tamaño tan pequeño no había espacio más que para lo que de verdad le importaba a Joan, que era sencillamente saber de su padre y de su familia. La carta se cierra con el recuerdo que Joan tiene hacia su tía y sus hermanas

11 “vos he scrit per altre letra, vos he tremeses per lo senyor en Curós Tixedor". (Doc. 1).

12 "La rahó perquè se’n torna lo Tardiu per quant li an dit son pare és mort per axò se’n és tornat" (Doc. 1).

SCRIPTA, Revista internacional de literatura i cultura medieval i moderna, núm. 18 / desembre 2021 / pp. 57-80 ISSN: 2340-4841 · doi:10.7203/SCRIPTA.18.21716 
Luis Almenar Fernández. Lo vostre humil fill, qui us desiga molt veure. Cartas del apotecario rosellonés Joan Pereta desde Valencia a su padre en Perpiñán (1474-1479)

pequeñas, Joaneta, Aldonça, Caterina y Margarina, así como hacia sus "bons amichs" en Perpiñán, a quienes se encomienda y transmite sus mejores deseos. ${ }^{13}$

No sabemos quién llevó finalmente esta carta a Jaume Pereta a Perpiñán, si fue Enrique Reis o Tardiu hijo. De lo que no cabe duda es de que, a bordo de aquella galera, acompañando a los jóvenes roselloneses a través de las aguas del Mediterráneo, la carta llegó finalmente a la Font Nova de Perpiñán, quizás donde Jaume tenía su notaría, o quizás su vivienda particular. La misiva cumplió su cometido, y supuso el inicio de un cruce de cartas que continuó entre Joan y Jaume, entre Valencia y Perpiñán, durante varios años, a pesar de la tortuosa situación que atravesó el Rosellón en este período.

Figura 2. La situación de la Font Nova en el trazado urbano de Perpiñán

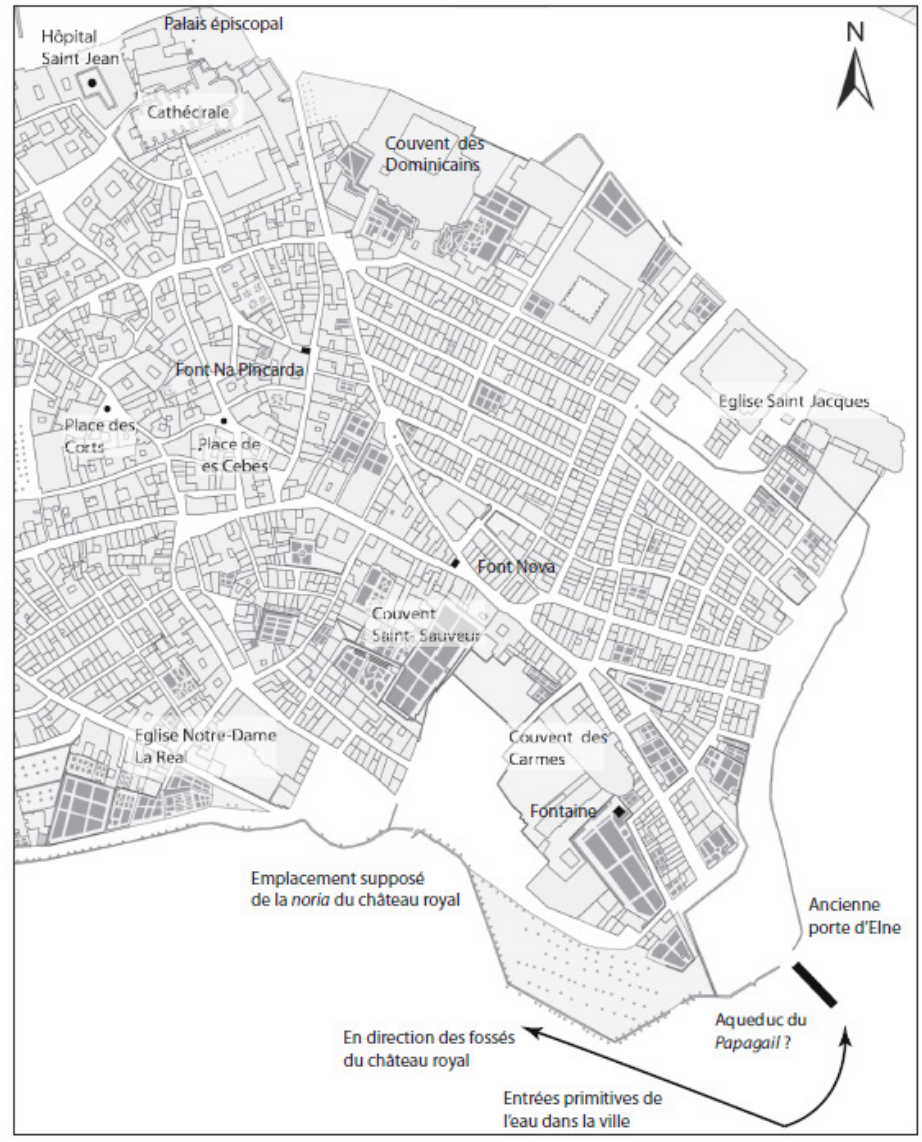

Fuente: Puig / Carozza / Durand 2015: 73.

13 "No he més a dir per la present, recoman-me molt a vos e a la mia cara thia e a Johaneta, Aldonça, Cathalina e a Margarida e a tots los bons amichs" (Doc. 1).

SCRIPTA, Revista internacional de literatura i cultura medieval i moderna, núm. 18 / desembre 2021 / pp. 57-80 ISSN: 2340-4841 $\cdot$ doi:10.7203/SCRIPTA.18.21716 
Luis Almenar Fernández. Lo vostre humil fill, qui us desiga molt veure. Cartas del apotecario rosellonés Joan Pereta desde Valencia a su padre en Perpiñán (1474-1479)

Figura 3. La Font Nova en la calle de la universidad de Perpiñán (siglo XIX)

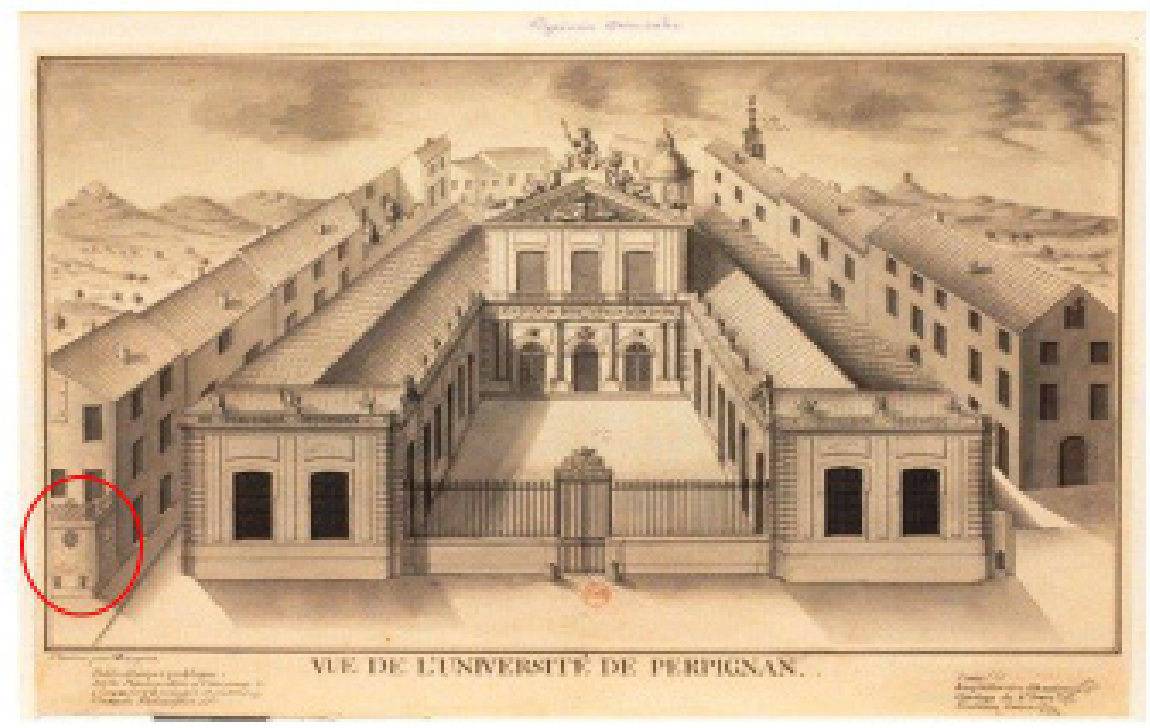

\section{Carta de 9 de agosto de 1479}

Al contrario que la carta de 1474, que sugería la existencia de un largo período en el que Joan no había recibido cartas de su padre, la de 1479 revela que entre ambos años tuvo lugar el intercambio de varias misivas, que habían confirmado a Joan el bienestar de su padre y de su familia. Y así, el tono de preocupación desmesurada de la misiva anterior desaparece en esta carta para dar lugar a una conversación mucho más sosegada, en ocasiones trivial, sobre asuntos de los que se había estado hablando en cartas anteriores, las cuales no conservamos, incluyendo planes para un futuro reencuentro.

La misiva del 9 de agosto de 1479 se redactó a raíz de que, un día antes, Joan hubiera recibido en Valencia una carta de su padre desde Perpiñán. El apotecario leyó la misiva con una gran ilusión, dado que hacía al menos un año y medio (“de XVIII a XX mesos") que no recibía correspondencia de Jaume. ${ }^{14}$ La ausencia del aura de inquietud de la carta de 1474, a pesar del tiempo que había pasado desde la recepción de la última misiva -lo cual debió acontecer, pues, en 1477 o 1478-, hace pensar que el intercambio de cartas había sido muy fluido al menos los primeros años tras la recepción de la misiva de 1474. En cualquier caso, la carta de 1479 de Jaume Pereta había llegado a Valencia en una "galeaça de França". Joan explica que cuando la embarcación atracó en Valencia él se hallaba en Castilla, por lo que no había podido responderle antes, ni a su padre ni a su tío

14 “no 'm podeu ffer mayor glòria sinó aver letres vostres, car jurar-vos puch més avia de XVIII o XX mesos no n'avia aguda nenguna" (Doc. 2).

SCRIPTA, Revista internacional de literatura i cultura medieval i moderna, núm. 18 / desembre 2021 / pp. 57-80 ISSN: $2340-4841 \cdot$ doi:10.7203/SCRIPTA.18.21716 
Luis Almenar Fernández. Lo vostre humil fill, qui us desiga molt veure. Cartas del apotecario rosellonés Joan Pereta desde Valencia a su padre en Perpiñán (1474-1479)

Simon Llombart, cuyas cartas también habían llegado en la misma embarcación. ${ }^{15}$ Esto sugiere que, como otros apotecarios, Joan Pereta no solo debía de trabajar en una botica de la ciudad de Valencia, donde se situaría la residencia a la cual las cartas de su padre iban consignadas, sino que también comercializaba sus productos por otros espacios de la península Ibérica (Ferragud 2007: 48-57). Joan se excusa y ruega a Jaume que no se enfade ("no us ne maravelleu") y que comprenda la dilación en su respuesta, y que no se sorprenda si, cuando regrese de nuevo la galeaza de Valencia a Perpiñán, no hay cartas suyas a bordo, porque aún no había podido contestarle. ${ }^{16}$

El resto de la carta está estructurada a través de los diferentes temas sobre los que Jaume le había escrito en la carta inmediatamente anterior, que no conservamos, y a los que da respuesta. Jaume le había contado que se encontraba bien de salud, lo cual alegraba a Joan, también en buen estado, puesto que se hablaba en Valencia de que en Perpiñán estaba muriendo mucha gente "en stranya manera", seguramente en referencia a algún tipo de brote epidémico. ${ }^{17}$

Por otra parte, Jaume le había insistido mucho a su hijo en su última carta en que volviera a Perpiñán con él y su familia. Joan, enternecido, le da su palabra de que es consciente de lo mucho que él y sus parientes desean verle, y les confirma sus deseos de reunirse de nuevo y de volver a casa. Es más, el joven confiesa que, si hubiera recibido la carta de su padre cuando la galeaza de Francia aún estaba atracada en Valencia, no habría esperado ni un instante para subirse en ella, revelando que esta iba de retorno a Perpiñán. ${ }^{18}$ Los asuntos de Joan en Valencia, no obstante, le impedían regresar por el momento a la capital del Rosellón, pero le confirmaba a su padre que no tardaría envolver con él y los suyos ("molt prest e més que no us pensau yo seré ab vosaltres") (Doc. 2), rogando que no se enfadaran y que lo comprendieran, y que rezaran por él.

Un tercer asunto sobre el que Jaume había escrito a Joan, y sobre el que este ahora contestaba, era al respecto de los regalos que las hermanas de Joan pedían que trajera a su regreso de Valencia. "Aquexes infantes", como las llamaba el joven apotecario, le rogaban que les llevara a Perpiñán "un li de tovalloles de seda" para cada una de ellas, ${ }^{19}$ tejido que comenzaba a adquirir una enorme importancia y que alcanzaría su culmen en los siglos venideros (Navarro Espinach, 1995). A sabiendas de que se trataba de algo caro, Jaume se había ofrecido a pagarle lo que costaran

15 "perquè dita letra venia sots letres de mon uncle en Simó Lombart (...) yo no aguí dita letra fins ara que és stat vengut" (Doc. 2).

16 "e perquè crech sereu stat enugat, com ab la dita galeaça no us e scrit, no us ne meravelleu. Per quant yo no avia agudes lletres vostres no tenia ocasió d'escriure. Ara pus n’e aguda, vos respondré al contengut de aquella” (Doc. 2).

17 “Ab dita letra me avisau de vostra bona sanitat, de què és cosa que 'n tinch molt pler, si bé n'estava ab conguxa, per quant así diuen que ss moren aquí en stranya manera, de què prech aureu senyor Déu” (Doc. 2).

18 "siau cert que, com la galeaça és stada açí yo agués rebuda la lletra, que ara e aguda, yo no aguera sperat punt ni ora que fos pugat ab ella" (Doc. 2).

19 "me avisau com aquexes infantes me preguen que ls port a cascuna un li de tovalloles de seda" (Doc. 2).

SCRIPTA, Revista internacional de literatura i cultura medieval i moderna, núm. 18 / desembre 2021 / pp. 57-80 ISSN: $2340-4841 \cdot$ doi:10.7203/SCRIPTA.18.21716 
Luis Almenar Fernández. Lo vostre humil fill, qui us desiga molt veure. Cartas del apotecario rosellonés Joan Pereta desde Valencia a su padre en Perpiñán (1474-1479)

dichas telas a su hijo, una vez se hubiera consumado su vuelta en la capital rosellonesa. El joven apotecario no solo no aceptaba la propuesta de su padre, sino que, como adulto emancipado, se sintió ofendido, comunicando a Jaume que no solo no aceptaría cobrar por los presentes para sus hermanas, sino que tal propuesta le enojaba profundamente ("molt enug me'n feu"). ${ }^{20}$ Joan se mostraba complacido, no obstante, del "memorial” que le había enviado Jaume a Valencia junto con la carta anterior, quizás de productos locales que llevar a Perpiñán, sobre lo cual Joan se complacía a llevarlos a la ciudad rosellonesa en la medida de sus posibilidades. ${ }^{21}$

Como en el caso anterior, la carta de 1479 se cierra con la encomienda acostumbrada a su padre, a su tía y a sus hermanas. Es llamativa, en este caso, la referencia a "na Morada", quien no aparecía entre las mujeres de la carta de 1474, y la ausencia de "Margarida", sobre quien no se hace mención en esta misiva (Docs. 1 y 2).

\section{Emociones y aspectos de mentalidad}

El lenguaje íntimo y personal de las cartas de Joan Pereta permite ir más allá de los asuntos tratados entre padre e hijo y de la reconstrucción del sistema de envíos de este tipo de documentación personal. Las cartas nos aproximan además al mundo de las emociones de Joan, de aquello que sentía en el momento de redactarlas, y así pueden observarse diversos aspectos que podríamos calificar "de mentalidad", de relevancia para aproximarnos a la personalidad del apotecario y al tipo de relación con su padre.

Como no podía ser de otra manera en la Edad Media, Joan Pereta se revela como una persona profundamente cristiana. Las referencias a Dios salpican ambos textos hasta en siete ocasiones, algo nada desdeñable en dos cartas tan breves. Estas consisten a veces en ruegos por el bienestar de su padre, su familia y él mismo - "Déu per sa merçé vos ho conserve en tot bé, amén”, "Déu per la sua infinida potència vos trameta sanitat", "Déu us tinga en sa guarda, amén", "pregau a Déu mi endreçe com lo meu cor desiga", "si a Déu será plasent molt prest e més que no us pensau yo seré ab vosaltres"-, y en otras ocasiones en agradecimientos por su buena salud -"per lo present [la salud] és bona al manar de Déu", "per la gràcia de Déu scrich ben ssa". A ello se añaden aún invocaciones a la Trinidad -"la Santa Trinitat sia de vos e de mi guarda, amén"- y referencias a su fe personal - "per ma fe podeu creure que per molt desigs que vos ni mos parents tingueu de la mia vista yo "n tinch molt més de la de vosaltres" (Docs. 1 y 2).

La relación de Joan con Jaume, sin duda afectuosa, se desarrolla en unos términos rotundamente formales y respetuosos, siguiendo unas cordialidades que poco tienen que ver con las relaciones

20 "És cosa demesiada de vós dir-me que com sia aquí m o pagareu, car vós sabeu bé que, per molt que yo pogués fer per vós ni per coses vostres, may vos poria satisfer la obligació que us tinch, e axí, feu-me tanta de gràcia no vullau pensar en dir-me tals paraules, que molt enug me’n feu" (Doc. 2).

21 “Molt pler e prés del memorial que m’aveu enviat, que ab ància que poria portar aquí, perquè ab totes mes fforçes me dispondré proveyr al que a mi serà posible”. (Doc. 2).

SCRIPTA, Revista internacional de literatura i cultura medieval i moderna, núm. 18 / desembre 2021 / pp. 57-80 ISSN: $2340-4841 \cdot$ doi:10.7203/SCRIPTA.18.21716 
Luis Almenar Fernández. Lo vostre humil fill, qui us desiga molt veure. Cartas del apotecario rosellonés Joan Pereta desde Valencia a su padre en Perpiñán (1474-1479)

paternofiliales actuales. Recuerdan mucho, de hecho, a aquellas que se desarrollaban aún a principios del siglo XX, en las que los hijos se dirigían a sus progenitores de "usted". Joan, de hecho, habla en todo momento a su padre de "vos", como por otra parte era cotidiano en la mayor parte de contextos sociales en la época medieval y, desde luego, vemos que lo podía ser también en el ámbito familiar. Es llamativo, por otra parte, las actitudes de respeto que pueden encontrarse en ambas cartas, inspiradas directamente en la ideología feudal. Joan se dirige a su padre de la misma manera que un vasallo lo hace a su señor. "Lo qui us bessa mans e peus, Johan Pereta, fill vostre. Prest al que manareu tostemps", es la frase que cierra la carta de 1474 (Doc. 1). Estos formalismos, casi serviles, en los que Joan se pone al completo servicio de su padre, los encontramos igualmente en las referencias a su tía y a sus hermanas, cuando Joan se encomienda a todos ellos -"que m coman molt en gràcia e merçé vostra”-, situándose, pues, voluntariamente bajo su protección y servicio (Doc. 2).

Ni el fervor religioso ni la actitud reverente de Joan hacia su padre eran, desde luego, excepcionales, pues eran plenamente representativos de los comportamientos y la moralidad habitual del momento. Ambas cosas, de hecho, tienen una presencia notable en las diversas cartas personales identificadas por otros historiadores e historiadoras. Un ejemplo destacable, por tratarse precisamente de otro catalán que escribió a su padre desde Valencia, lo aportan las misivas del aprendiz de notario Pere Puigvert. En estas se despedía siempre con las expresiones "e lo bon Jesús sia ab tots", "la Santa Trinitat sia ab tots" o "nostre senyor vestra virtuosa persona guarde com desiga" (Lozano Gracia 2007: 147). A ello hay que añadir, por otra parte, fórmulas de profundo respeto familiar que encontramos presentes en idéntica forma en las cartas de Joan Pereta, por ejemplo, "prest al que maneu" o "vostre fill, qui les mans vos besa". (Lozano Gracia 2007: 158, 164). Son, en cualquier caso, expresiones que debían de ser comunes en las relaciones interpersonales y familiares de la época, como muestra su presencia recurrida en muchas otras cartas de las identificadas por otros investigadores e investigadoras (véase la recopilación de expresiones de fervor religioso presentes en este tipo de misivas privadas en Martorell, 1926: 14-16).

\section{Conclusiones}

Muy lejos de poder imaginar el mundo medieval como conformado por unas sociedades distantes, cerradas en sí mismas y de contactos meramente puntuales, las cartas de Joan Pereta se suman a las otras evidencias epistolares que dibujan un mundo Mediterráneo profundamente interconectado, en el que la información se transmitía de manera rápida. Las noticias que circulaban por escrito lo hacían de forma eficaz, desde luego, en la forma de cartas de carácter político y comercial, dado que el interés por saber de asuntos como la guerra y los mercados generaron un volumen de documentación epistolar sobradamente conocido. Parte del abundante flujo de cartas que se movía por el Mediterráneo de la época, no obstante, también era conformado por las misivas de individuos particulares, de extracción no privilegiada, como las de Joan y Jaume Pereta, quienes 
Luis Almenar Fernández. Lo vostre humil fill, qui us desiga molt veure. Cartas del apotecario rosellonés Joan Pereta desde Valencia a su padre en Perpiñán (1474-1479)

eran capaces de comunicarse entre puntos alejados de la península Ibérica. Las cartas de Joan Pereta se suman así a las otras que de manera fortuita se hallan "perdidas" entre las páginas de los protocolos notariales de la Corona de Aragón, a la espera de ser encontradas por los y las profesionales de la historia. Son misivas de mercaderes, notarios y profesionales urbanos de todo tipo, de hombres y, no lo olvidemos, de mujeres, que escribían a amigos, conocidos y familiares, por fines meramente emocionales. Son intereses que, aunque puedan parecer comparativamente triviales, sin duda ayudaron al desarrollo de un verdadero sistema postal que ya estaba plenamente establecido en el siglo XV.

Las cartas escritas en Valencia por el apotecario Joan Pereta, de quien lamentablemente hemos podido averiguar muy poco en comparación con su padre, han permitido realizar un modesto ejercicio de microhistoria, que ayuda a comprender los mecanismos de transmisión de la información en la época bajomedieval. Pero, ante todo, las cartas arrojan luz de una historia familiar particular, marcada por la separación, la distancia y la lejanía de Joan Pereta con respecto a su padre, su tía, sus hermanas, su madrastra y sus amigos. El deseo de Jaume era que su hijo regresara a Perpiñán con los suyos y, como hemos visto, Joan tenía en mente regresar a casa en cuanto sus asuntos en Valencia se lo permitieran. Si el reencuentro finalmente se produjo, ciertamente, ya nunca lo sabremos. Esperemos que así fuera. 
Luis Almenar Fernández. Lo vostre humil fill, qui us desiga molt veure. Cartas del apotecario rosellonés Joan Pereta desde Valencia a su padre en Perpiñán (1474-1479)

\section{Bibliografía}

Cahner, M. (1977-1978) Epistolari del Renaixement, 2 vols. Valencia, Albatros.

Camargo, M. (1991) Ars dictaminis. Ars dictandi, Turnhout, Brepols.

Camps, Ch. (1973) Les noms des rues de Perpignan, Tesis doctoral inédita, Montpellier, Université Paul Valéry.

Castillo Gómez, A. (2002) "Del tratado a la práctica. La escritura epistolar en los siglos XVI y XVII", en Sáez, C. / Castillo, A. (eds.), La correspondencia en la Historia. Modelos y prácticas de la escritura epistolar. Actas del VI Congreso Internacional de Historia de la Cultura Escrita, Madrid, Calambur, 2002, pp. 79-107.

Catafau, A. / Bergeret, A. / Fontaine, D. / Recolin, A. (2014), “La distribution de l'eau à Perpignan au Moyen Âge: l'apport des témoignages archéologiques et écrits”, en Catafau A. / Passarrius O. (eds.), Un palais dans la ville. Vol. 2: Perpignan des rois de Majorque, Canet, Trabucaire, pp. 159-174.

Feliu, G. (1999) "La demografia baixmedieval catalana. Estat de la qüestió i propostes de futur", Revista d'història medieval, 10, pp. 13-44.

Ferragud, C. (2007), "Metges, cirurgians, barbers i apotecaris: l'assistència médica a la València baixmedieval”, Mètode. Revista de difusió de la investigació, 53, pp. 48-57.

Ferrer i Mallol, Ma . T. (1974) "La redacció de l'instrument notarial a Catalunya. Cèdules, manuals, llibres i cartes", Estudios históricos y documentos de los archivos de protocolos, IV, pp. 29-191.

Ferrer i Mallol, Mª T. (1980) "Cartes i billets privats en els manuals del notari barceloní Narcis Guerau Gili (segle XV)”, en Miscel lània Ramon Aramon i Serra, II, Barcelona, Curial, 1980, pp. 197-217.

Fontaine, D., Archives départementales des Pyrénées-Orientales. Guide des archives notariales, en curso de elaboración.

Gimeno Blay, F. M. (2005) "Missivas, mensageras, familiares... Instrumentos de comunicación y de gobierno en la España del quinientos", Anuario del Centro de Estudios Históricos "Prof. Carlos S. A. Segreti", 5, 15, pp. 23-36.

Iciar, J. (1552) Nuevo estillo d'escrevir cartas mensageras sobre diversas materias, Zaragoza.

Jardin, J-P., Marin, A., Rochwert-Zuili, P. y Thieulin-Pardo, H. (2020) (dirs.), Correspondencias entre mujeres en la Europa medieval, Paris, e-Spania Books.

Lozano Gracia, S. (2007) “Las cartas de un aprendiz de notaría. Pere Puigvert (1502-1511)”, Recerca, 11, pp. 139-170.

Martín, P. (2005) El arte epistolar en el Renacimiento europeo, 1400-1600, Bilbao, Universidad de Deusto.

Martínez Vinat, J. (2018) Cofradias y oficiós. Entre la acción confraternal y la organización corporativa en la Valencia medieval (1238-1516), Tesis doctoral inédita, Valencia, Universitat de València.

SCRIPTA, Revista internacional de literatura i cultura medieval i moderna, núm. 18 / desembre 2021 / pp. 57-80 ISSN: $2340-4841 \cdot$ doi:10.7203/SCRIPTA.18.21716 
Luis Almenar Fernández. Lo vostre humil fill, qui us desiga molt veure. Cartas del apotecario rosellonés Joan Pereta desde Valencia a su padre en Perpiñán (1474-1479)

Martorell, F. (1926), Epistolari del segle XV. Recull de cartes privades, Barcelona, Barcino.

Mesquida, J. A. (2003) 'L'arty stil para scriure a totes persones de qualsevol estat que sien. E diverses maneres de comptes abreviats molt necessaris per a totes persones, de Thomàs de Perpenyà. Un manual de correspondència de principis del segle XVI", en Zimmermann, M-C. / Charlon, A. (eds.), Actes del dotzè Col loqui Internacional de Llengua i Literatura Catalanes: Universitat de París IV-Sorbonne, 4-10 de setembre de 2000, Barcelona, Publicacions de l'Abadia de Montserrat, pp. 317-329.

Murphy, J. (1986) La retórica en la Edad Media. Historia de la teoría de la retórica desde San Agustín hasta el Renacimiento, México, Fondo de Cultura Económica.

Navarro Bonilla, D. (2003) "Los archivos del sentimiento: función y representaciones de billetes y papeles de amor en la Edad Moderna", en Pliegos de Bibliofilia, 22, pp. 11-32.

Navarro Espinach, G. (1995), Industria y artesanado en Valencia, 1450-1525. Las manufacturas de seda, lino, cáñamo y algodón, Valencia, Publicacions de la Universitat de València, 4 vols.

Orlandi, A. (2008) Mercaderies i diners: la correspondència datiniana entre València i Mallorca (1395-1398), Valencia, Publicacions de la Universitat de València.

Pifarré, D. (1999) "La transmissió de la informació i la seva importància en el comerç internacional baixmedieval", Acta historica et archaeologica mediaevalia, 20, pp. 683-697.

Pifarré, D. (2002) El comerç internacional de Barcelona i el mar del Nord (Bruges) al final del segle XIV, Barcelona, Publicacions de l'Abadia de Montserrat.

Pontón, G. (2002) Correspondencias. Los orígenes del arte epistolar en España, Madrid, Biblioteca Nueva.

Poster, C. / Mitchell, L.C. (eds.) (2007) Letter-writing manuals and instruction from Antiquity to present, Columbia, University of South Carolina Press.

Puig, C. / Carozza, J-M. / Durand, S. (2015), "L'approvisionnement en eau de la ville de Perpignan (Pyrénées-Orientales) au Moyen-Âge et à l'Époque moderne : premiers éléments d'enquête", Archéologie du Midi Médiéval, 33, pp. 55-76.

Richardson, M. (2007) “The 'ars dictaminis', the formulary and medieval epistolary practice”, en Poster, C. / Mitchell, L.C. (eds.), Letter-writing manuals and instruction from Antiquity to present, Columbia, University of South Carolina Press, pp. 52-66.

Riu, M. (1979) "Cartes privades del segle XV a l'Arxiu de Santa Maria del Mar", Estudis universitaris catalans, 23, pp. 501-506.

Rodrigo Pertegás, J. (1929) "Boticas y boticarios. Materiales para la historia de la farmacia en Valencia en la centuria décima-quinta", Anales del Centro de Cultura Valenciana, 4, pp. 110-153.

Saguer, R. (2020) La rocuration royale des comtés de Roussillon et de Cerdagne (XIVe-début du XVe siècle): politiques patrimoniales, finances et administration du domaine royal sous Pierre IV, Jean Ier et Martin d'Aragon, 1344-1410, Tesis doctoral inédita, Perpiñán, Université de Perpignan.

Salrach, J. M. / Duran, E. (1980), Història dels Països Catalans. Dels origens a 1714, vol. 2, Barcelona, Adhasa.

SCRIPTA, Revista internacional de literatura i cultura medieval i moderna, núm. 18 / desembre 2021 / pp. 57-80 ISSN: 2340-4841 · doi:10.7203/SCRIPTA.18.21716 
Luis Almenar Fernández. Lo vostre bumil fill, qui us desiga molt veure. Cartas del apotecario rosellonés Joan Pereta desde Valencia a su padre en Perpiñán (1474-1479)

Serra i Ràfols, E. (1952) "Cinc lletres privades catalanes del segle XIV”, Butlletí de la Societat Catalana d'Estudis Històrics, 1, pp. 25-31.

Valldecabres, R. (ed.) (2002), El cens de 1510. Relació de focs valencians ordenada per les corts de Montsó, Valencia, Publicacions de la Universitat de València.

Vinyoles Vidal, T-M. (1984) "Cartes d'una catalana del segle XIV al seu marit", Estudis universitaris catalans, 26, pp. 387-420.

Vinyoles Vidal, T-M. (1996) "L'amor i la mort al segle XIV. Cartes de dones", Miscellània de textos medievals, 8, pp. 111-198.

Vinyoles Vidal, T-M. (2000) “Cartes de dones en el pas de l'Edat Mitjana al Renaixement", en Barceló Crespí, M. (ed.), Al tombant de l'Edat Mitjana. Tradició medieval i cultura bumanista. XVIII Jornades d'Estudis Històrics Locals, Palma, Institut d'Estudis Baleàrics, pp. 555-566.

Vinyoles Vidal, T-M. (2003-2004) "Unes cartes de dones del segle XV. Notes sobre la crisis feudal”, Acta bistorica et archaeologica mediaevalia, 25, pp. 445-460.

Viu Fandós, M. (2016) "Información y estrategias comerciales en la Corona de Aragón. La correspondencia de la compañía Torralba (1430-1432)", en Laliena, C. / Lafuente, M. (coords), Consumo, comercio y transformaciones culturales en la Baja Edad Media: Aragón, siglos XIV y XV, Zaragoza, Universidad de Zaragoza, pp. 125-146. 
Luis Almenar Fernández. Lo vostre humil fill, qui us desiga molt veure. Cartas del apotecario rosellonés Joan Pereta desde Valencia a su padre en Perpiñán (1474-1479)

\title{
Transcripciones
}

\section{Documento 1}

\author{
+ Ihesus. En València, a XXV d'abril 1474 +
}

Molt amat e de mi car pare. La causa de la present serà per avisar-vos com air que que (sic) teníem XXIIII vos he scrit per altre letra, vos he tremeses per lo senyor en Curós Tixedor, no obstant vos scrivís per en Antoni Reys, mas per quant aqueys ere pus prest, doní-los a ell perquè pens que aquella o per aquesta sereu avisat de mi, no restant ja ssiau stat avisat per moltes e diverses letres de les quals may de ninguna no he agut resposta, no ssé per què ni per què no resta per no aver-les agudes. Mas tinch a penssar que de tantes com vos ne trameses no pot ésser stat no n'agau agut nenguna, de les quals de dia en dia conffiava aver resposta. E may no ha trobat lo camí, ni per lo semblant de mon cosin germà, en Pere Torís, que n de tant de temps enssà que yo sse és en Barchinona may no és stant bastant d'escriure un mot de letra, volén dir "no ssab que yo ssia açí", dich-vos que per amichs, ssens yo, li he scrit X ho XII letres, que may no m'a volgut ffer resposta, ni per letra ni per paraula. Tinch a creure me vol mal de alguna cosa, no ssé li aga fet anugs nenguns. "Mas recorrent a vós lexem anar totes aquestes coses, vos prech per ara, e per quant lo pasatge stà ubert, vós me scrivau alguna letra en la qual me aviseu de mon pare, si 'n sabreu res, com stà ni si és és (sic) mort ni viu, perquè ya sabeu que d'ell may n'auria noves sinó per mityà vostre". E per ço vos prech molt carament vos me'n aviseu larga[ment] e del vostre stament axí mateyx, jatssessia sia stat molt ffort e de gran conguxa, mas ab tot axò vos prech me'n aviseu ya per la susdita letra que us he scrita, vos he avisat pus llargament, ara per aquesta me vull abreugar. Lo portador de la present, lo qual me pens serà lo fill d'en Tardiu, vos avisarà de mi, o per lo semblant lo desús dit Antoni Reys vos avisarà també, car abdós se'n van aquí ensemps ab la gal lera florentina. Per la hu o per l'altra aureu la present. La rahó perquè se'n torna lo Tardiu, per quant li an dit son pare és mort, per axò se n'és tornat, car ell, per deliberació d'estar açí ere vengut e, de ffet, avia ja trobat recapte, que stava ab un mercad[er], mas per causa de la sua mala nova a deliberat tornar-sse'n. Ell ssó sert vos avisarà de mi. Per la gràcia de Déu stich ben ssa e un poch alegre per lo deliurament aveu agut, car ssou ixit un poch de ffortuna. Déu per sa merçé vos ho conserve en tot bé, amén. No he més a dir; per la present recoman-me molt a vós e a la mia cara thia e a Johaneta, Aldonça, Cathalina e a Margarida e a tots los bons amichs. Ssi may me degués ffer per mi, ffeu-me resposta, car de açí avant no ssé de què 'm scriga; almeyns si avia letres de vós ffer-vos-hia resposta e ocórrer-m’ien altres coses e ffer-vos-hi a resposta, axí que prech-vos nos scrigam ssoviynt e que comensseu vós ara, per quant yo he comenssat ja haurà un jorn d'aquests un anyn, non pus. La Santa Trinitat sia de vós e de mi guarda, amén.

Lo qui us bessa mans e peus, Johan Pereta, fill vostre. Prest al que manareu tostemps.

Dorso:

Al molt amat e car pare, lo senyor en Jaume Pereta, notari, prop la Ffont Nova.

En Perpinyà (signum)

Per amich

Fuente: ADPO, 1 B223 (folio suelto sin foliar)

SCRIPTA, Revista internacional de literatura i cultura medieval i moderna, núm. 18 / desembre 2021 / pp. 57-80 ISSN: $2340-4841 \cdot$ doi:10.7203/SCRIPTA.18.21716 
Luis Almenar Fernández. Lo vostre humil fill, qui us desiga molt veure. Cartas del apotecario rosellonés Joan Pereta desde Valencia a su padre en Perpiñán (1474-1479)

\section{Documento 2}

+ Ihesus Christus. En València, a VIIII de agost, 1479 +

Molt magnífich senyor e de mi car pare. Air que comptàvem.VIII. del present, rebí una letra vostra feta aquí en Perpinyà. Com la galeaça de Ffrança vingué e perquè dita letra venia sots letres de mon uncle, en Simon Lombart, en aquelles hores que dita galeaça fou junta açí, nos trobà en ciotat, que era en Castella, e axí yo no aguí dita letra fins ara, que és stat vengut. E perquè crech sereu stat enugat, com ab la dita galeaça no us e scrit, no us ne meravelleu. Per quant yo no avia agudes lletres vostres no tenia ocasió d'escriure. Ara, pus n'e aguda, vos respondré al contengut de aquella.

Ab dita letra me avisau de vostra bona sanitat, de què és cosa que $n$ tinch molt pler, si bé n'estava ab conguxa, per quant así diuen que 's moren aquí en stranya manera, de què prech nostre senyor Déu, per la sua infinida potència, vos trameta sanitat, com tots vosaltres desigau. Si de la mia vos plau saber, per lo present és bona al manar de Déu e vostra.

Més, me dieu que yo vaga aquí. Per ma ffe podeu creure que per molt desigs que vós ni mos parents tingueu de la mia vista, yo 'n tinch molt més de la de vosaltres. E siau cert que, com la galeaça és stada açí, yo agués rebuda la lletra que ara e aguda, yo no aguera sperat punt ni ora que fos pugat ab ella. Emperò com yo viu que de mi no avíeu feta menció ab un tal pasatge com era aquest, totes les ganes me'n fugiren de anar, de què sertament ne restí molt agreugat, car tenia cregut me aguéseu oblidat. Emperò si a Déu serà plasent, molt prest e més que no us pensau yo seré ab vosaltres, car yo n tinch ben vista la rahó no us vull asignar [quinas] ni quant no perquè no està en ma mà. Emperò yo hi daré tal diligència que será honor mia e de vosaltres e sens molta dilació, perquè us prech no us enugeu, que yo ffaré content a tots vosaltres. Pregau a Déu mi endreçe com lo meu cor desiga.

Axí matex, me avisau com aquexes infantes me preguen que ls port a cascuna un li de tovalloles de seda. És cosa demesiada de vós dir-me que com sia aquí m o pagareu, car vós sabeu bé que, per molt que yo pogués fer per vós ni per coses vostres, may vos poria satisfer la obligació que us tinch, e axí feu-me tanta de gràcia, no vullau pensar en dir-me tals paraules, que molt enug me'n feu. Car en lo meu cor tinch ben penssat de portar-los coses, que vós hi elles seran ben contentes, e aquexa és ma intenció de servir-les, no tant com elles merexen, mas ab lo meu poch poder, que ja tinch stuga[des] açí moltes coses per a portar aquí. Molt pler e prés del memorial que m’aveu enviat, que ab ància que poria portar aquí, perquè ab totes mes fforçes me dispondré proveyr al que a mi serà posible.

E per la present no he més a dir, sinó que m coman molt en gràcia e merçé vostra e de mado[na] ma tia, e a na Norada, e a Johana, Aldonça e Catarina, a totes en general, e a cascun[a] en special, pregant-vos molt tostemps que aureu posibilitat d'escriure que $\mathrm{m}$ scrigau, que de rres no $\mathrm{m}$ podeu ffer mayor glòria, sinó aver letres vostres, car jurar-vos puch més avia de XVIII o XX mesos no n'avia aguda nenguna, perquè us [prech] carísimament vos hi vullau delitar per la consolació mia.

Ffeu-me tanta de merçé, la present letra aga bon recapte, que va a Vinçà. [Es]criviu senyor mon pare de part vostra que stiga alegre, que tantost seré ab ells, e Déu vos tinga en sa guarda, amén.

Lo vostre humil fill, qui us desiga molt veure. Johan Pereta, apotecari.

SCRIPTA, Revista internacional de literatura i cultura medieval i moderna, núm. 18 / desembre 2021 / pp. 57-80 ISSN: $2340-4841 \cdot$ doi:10.7203/SCRIPTA.18.21716 
Luis Almenar Fernández. Lo vostre bumil fill, qui us desiga molt veure. Cartas del apotecario rosellonés Joan Pereta desde Valencia a su padre en Perpiñán (1474-1479)

Dorso:

$\mathrm{Al}$ molt honorable lo senyor en Jaume Pereta, notari, prop la Font Nova. En Perpinyà. Per via de Barchinona.

Fuente: ADPO, 3E1/1202, fol. 64.

SCRIPTA, Revista internacional de literatura i cultura medieval i moderna, núm. 18 / desembre 2021 / pp. 57-80 ISSN: 2340-4841 · doi:10.7203/SCRIPTA.18.21716 